\title{
Mối quan hệ giữa sự suy kiệt cảm xúc, khả năng thích nghi và sự gắn kết của nhân viên người Việt trong các công ty đa quốc gia trên địa bàn Thành phố Hồ Chí Minh
}

\section{Exploring the relationships of Vietnamese employees' emotional exhaustion, adaptability and their commitment case study of multinational companies in Ho Chi Minh City}

\author{
Trần Thị Lệ Hiền ${ }^{1 *}$ \\ ${ }^{1}$ Trường Đại học Công nghiệp Thực phẩm Thành phố Hồ Chí Minh, Việt Nam \\ *Tác giả liên hệ, Email: hientt12011@gmail.com
}

\begin{tabular}{|c|c|}
\hline THÔNG TIN & TÓM TẮT \\
\hline $\begin{array}{l}\text { DOI:10.46223/HCMCOUJS. } \\
\text { econ.vi.15.3.1340.2020 }\end{array}$ & $\begin{array}{l}\text { Nghiên cứu được thực hiện nhằm kiểm định mối quan hệ } \\
\text { giữa sự suy kiệt cảm xúc (emotional exhaustion - } \mathrm{EE} \text { ), khả năng } \\
\text { thích nghi (adaptability - } \mathrm{AD} \text { ) và sự gắn kết của nhân viên người } \\
\text { Việt trong các công ty đa quốc gia trên địa bàn Tp. HCM về mặt }\end{array}$ \\
\hline Ngày nhận: 25/03/2020 & tình cảm (affective commitment - AC), lợi ích (continuance \\
\hline : 23/04/2020 & $\begin{array}{l}\text { commitment }-\mathrm{CC} \text { ) và đạo đức (normative commitment - NC). Sau } \\
\text { khi khảo sát } 212 \text { mẫu, dữ liệu thu thập sẽ được xử lý bằng phần }\end{array}$ \\
\hline Duyệt đăng: 27/04/2020 & $\begin{array}{l}\text { mềm SPSS } 25.0 \text { và AMOS } 20.0 \text {. Kết quả nghiên cứu cho thấy sự } \\
\text { suy kiệt cảm xúc có ảnh hưởng đến sự gắn kêt của nhân viên vì } \\
\text { tình câm và lợi ích. Sự thích nghi của nhân viên sẽ có ảnh hưởng } \\
\text { đến sự gắn kết về mặt đạo đức. }\end{array}$ \\
\hline
\end{tabular}

Tù khóa:

công ty đa quốc gia, khả năng thích nghi, sự gắn kết của nhân viên, sự suy kiệt cảm xúc

ABSTRACT
The research was conducted to investigate the relationship of
emotional exhaustion (EE), adaptability (AD) and their
commitment (affective commitment - AC, continuance
commitment - CC and normative commitment - NC). Data was
collected from 212 Vietnamese employees working for
international companies in HCM city. SPSS 25.0 and AMOS 20.0
approaches were used to analyze the data. The study results
showed that emotional exhaustion has affected on both affective
commitment and continuance commitment. Besides, adaptability
has an impact on normative commitment.

Keywords:

adaptability, emotional exhaustion, employee commitment, international company giữa sự suy kiệt cảm xúc (emotional exhaustion - EE), khả năng thích nghi (adaptability - $\mathrm{AD}$ ) và sự gắn kết của nhân viên người Việt trong các công ty đa quốc gia trên địa bàn $\mathrm{Tp}$. HCM về mặt commitment - CC) và đạo đức (normative commitment - NC). Sau khi khảo sát 212 mẫu, dữ liệu thu thập sẽ được xử lý bằng phần mềm SPSS 25.0 và AMOS 20.0. Kêt quả nghiên cứu cho thây sự tình cảm và lợi ích. Sự thích nghi của nhân viên sẽ có ảnh hưởng đên sự gắn kêt về mặt đạo đức.

The research was conducted to investigate the relationship of emotional exhaustion (EE), adaptability (AD) and their commitment (affective commitment - AC, continuance commitment - CC and normative commitment - NC). Data was collected from 212 Vietnamese employees working for international companies in HCM city. SPSS 25.0 and AMOS 20.0 approaches were used to analyze the data. The study results showed that emotional exhaustion has affected on both affective has an impact on normative commitment.

\section{Giới thiệu}

Trong nhiều năm trở lại đây, tình hình biến động và thiếu hụt nhân sự luôn là vấn đề mà nhiều doanh nghiệp chú trọng quan tâm, mở rộng đào tạo cả chiều rộng và chiều sâu. Theo khảo sát của Tập đoàn ManpowerGroup, tình trạng này là do đa số người Việt có xu hướng muốn làm việc tại nước ngoài hơn trong nước (Mai Dan, 2017). Nếu $10 \%$ là tỷ lệ nghỉ việc lý tưởng thì tỷ lệ nghỉ việc lên đến 19,1\%,20,5\% trong năm 2017, 2018 và dự đoán là $24 \%$ năm 2019 là một con số đáng báo động (Khong Loan, 2019). Theo số liệu của tổng cục Thống kê, TP. HCM là địa 
phương có lực lượng lao động trên 15 tuổi cao nhất nước (hơn 4 triệu người) nên tỷ lệ nghỉ việc của TP. HCM cũng đáng báo động. Vì khi nhân sự rời bỏ tổ chức, đặc biệt là những nhân sự nòng cốt, thì sẽ kéo theo hàng loạt những khó khăn, tổn thất về nhiều mặt như mất mát về tri thức, các mối quan hệ và tốn chi phí cho công tác tuyển chọn, đào tạo nhân sự mới. Điều này không những gây khó khăn cho hoạt động sản xuất kinh doanh của một doanh nghiệp cụ thể mà còn ảnh hưởng đến hoạt động của nhiều doanh nghiệp khác.

Toàn cầu hóa giúp mở rộng hợp tác thương mại giữa các nước và theo đó là sự ra đời của một số lượng lớn các công ty đa quốc gia. Thành phố Hồ Chí Minh, một trong những đô thị phát triển nhất nước, vẫn luôn là sự lựa chọn đầu tiên để các công ty đa quốc gia đặt trụ sở hay văn phòng đại diện. Nhân viên trong các công ty này sẽ đến từ nhiều vùng, lãnh thổ có văn hóa, lối sống, chính trị, xã hội khác nhau nên vấn đề nhân sự tại đây cũng rất phức tạp (Tarique \& Schuler, 2008). Trong đó, nổi bậc là vấn đề tuyển dụng, bổ nhiệm, duy trì nguồn nhân lực có chất lượng cao và hạn chế tối đa những thiệt hại về mọi mặt do việc biến động nhân sự gây ra; ngoài ra, các công ty thường cạnh tranh để thu hút đội ngũ nhân viên giỏi làm cho vấn đề cạnh tranh nhân lực càng khốc liệt (Collings \& Scullion, 2012). Trong các công ty đa quốc gia, chế độ lương, thưởng hay thăng tiến thường ít dựa vào thâm niên mà thường dựa vào năng lực làm việc nên các cá nhân phải phấn đấu hết mình để đạt được thành tích tốt. Sự cạnh tranh này ít nhiều cũng gây áp lực lên người lao động (Cole \& Bedeian, 2007), nhất là lao động người Việt với văn hóa lao động khác với các nước phương Tây và trình độ ngoại ngữ còn hạn chế.

Để duy trì lòng trung thành của người lao động và làm cho họ gắn kết hơn với tổ chức, doanh nghiệp đã tốn rất nhiều công sức lẫn tâm sức. Cole và Bedeian (2007) chứng minh được rằng, sự gắn kết của nhân viên bị ảnh hưởng ngược chiều bởi cảm xúc của họ dành cho công việc, mà cụ thể là sự suy kiệt cảm xúc. Công trình nghiên cứu của Ito và Brotheridge (2005) cũng biện luận được rằng của khả năng thích nghi là yếu tố quan trọng ảnh hưởng tới quyết định nghỉ việc của nhân viên. Bên cạnh công trình nghiên cứu của hai nhóm tác giả trên, có rất nhiều nghiên cứu thực nghiệm khác chứng minh được sự ảnh hưởng của yếu tố suy kiệt cảm xúc và yếu tố khả năng thích nghi của người lao động đến sự gắn kết của họ với tổ chức, nhưng rất ít nghiên cứu xem xét ba yếu tố trên trong cùng một mô hình. Vì vậy, bài nghiên cứu được thực hiện nhằm: (1) Kiểm định mức độ ảnh hưởng của giữa sự suy kiệt cảm xúc và khả năng thích nghi đến sự gắn kết của nhân viên; (2) Cung cấp một cách nhìn, một bức tranh bao quát và toàn diện hơn về mối quan hệ giữa các yếu tố, qua đó có thể đề xuất một số hàm ý giúp nhà quản lý các công ty đa quốc gia trên địa bàn TP. HCM giải quyết tốt bài toán biến động nhân sự của doanh nghiệp mình.

\section{Cơ sở lý thuyết và mô hình nghiên cứu}

\subsection{Cơ sở lý thuyết}

\section{Mối quan hệ giữa sụ suy kiệt cảm xúc và sụ gắn kết của nhân viên}

Theo Cole và Bedeian (2007), sự suy kiệt cảm xúc được hiểu là sự mệt mỏi, chán nản cả về thể chất lẫn tinh thần khi nhân viên cảm thấy hết năng lượng để tiếp tục làm việc. Tương tự, Karl và Peluchette (2006) cho rằng sự suy kiệt cảm xúc là sự cạn kiệt về cảm xúc của một cá nhân khi cảm thấy thiếu năng lượng. Và hiện tượng này xảy ra khi nhân viên rơi vào tình trạng căng thẳng quá mức (Grayson, 1998). Theo Hobfoll (2001), trong một doanh nghiệp, phần lớn người lao động sẽ quan tâm đến công sức họ bỏ ra với những giá trị họ muốn nhận lại. Khi nhân viên nhận thức rằng họ bỏ quá nhiều công sức hoặc mất quá nhiều năng lượng cho việc hoàn thành công việc nhưng thành quả mà họ được nhận lại không tương xứng thì sẽ dễ dẫn đến căng thẳng và suy kiệt cảm xúc (Hur, Park, \& Moon, 2014). Đây được xem là nguyên nhân quan trọng 
làm giảm mong muốn gắn kết với tổ chức (Cole \& Bedeian, 2007).

Khái niệm về sự gắn kết của người lao động với tổ chức được Porter, Steers, Mowday, và Boulian nhắc đến đầu tiên vào năm 1974. Theo đó, khái niệm này được hiểu là sự cố gắng duy trì là một thành phần của tổ chức. Tương tự, Mowday, Steers, và Porter (1979) cũng chỉ ra rằng sự gắn kết của người lao động với tổ chức là sự tích cực tham gia các hoạt động và xem mình là thành viên của tổ chức. Allen và Meyer (1990) xem đây là một trạng thái tâm lý thể hiện việc nhân viên có mong muốn duy trì ở lại làm việc và cống hiến cho tổ chức hay không. Các thành phần của sự gắn kết cũng không giống nhau trong từng nghiên cứu cụ thể do có rất nhiều định nghĩa khác nhau về sự gắn kết. Theo đó, yếu tố gắn kết bao gồm lòng trung thành (Loyalty) của nhân viên với tổ chức, sự đồng nhất (Identification) giữa mục tiêu, giá trị cá nhân với tổ chức và sự dấn thân (Involvement) vào các hoạt động (Mowday et al., 1979). Nhóm tác giả Allen và Meyer (1990) đã đề xuất và chứng minh rằng sự gắn kết của nhân viên với một tổ chức cụ thể có thể chia thành 3 loại dựa vào việc kế thừa công trình nghiên cứu của hai nhóm tác giả Porter và cộng sự (1974), Mowday và cộng sự (1979): (1) Gắn kết vì tình cảm (Affective commitment) là sự gắn bó về mặt cảm xúc tích cực (vui vẻ, hạnh phúc) của nhân viên đối với việc xác định và tham gia vào tổ chức; (2) Gắn kết vì lợi ích (Continuance commitment) liên quan đến việc nhân viên xem xét các chi phí khi nghỉ việc và (3) Gắn kết vì đạo đức (Normative commitment) đề cập đến cảm giác về việc nhân viên phải có nghĩa vụ và trách nhiệm tiếp tục ở lại và cống hiến cho tổ chức.

Thực tế cho thấy, có rất nhiều nghiên cứu kế thừa công trình của Allen và Meyer (1990). Trong nghiên cứu này, các khái niệm và thành phần của sự gắn kết cũng được kế thừa từ nghiên cứu của hai tác giả trên.

Theo thuyết "Bảo tồn nguồn năng lượng - conservation of resources theory", các cá nhân sẽ cố gắng bảo tồn nguồn năng lượng của bản thân để tránh tình trạng kiệt sức (Hobfoll, 2001). Đặc biệt là sự suy kệt cảm xúc sẽ làm cạn kiệt đáng kể nguồn tài nguyên cảm xúc của nhân viên, làm cho họ thận trọng hơn trong cách sử dụng các tài nguyên còn lại (Hobfoll, 2001; Hur et al., 2014). Việc mất quá nhiều năng lượng sẽ làm nhân viên cảm thấy căng thẳng và dẫn tới suy kiệt cảm xúc (Hobfoll, 2001). Cách tốt nhất để giảm sự suy kiệt này là giảm động lực làm việc (Wright \& Cropanzano, 1998), qua đó làm giảm mong muốn gắn kết với tổ chức (Cole \& Bedeian, 2007). Cole và Bedeian (2007) cũng chứng minh được rằng đối với nhân viên không quân Hoa Kỳ, với vai trò điều tiết của phong cách lãnh đạo chuyển đổi, sự gắn kết sẽ bị tác động bởi sự suy kiệt cảm xúc. Khi nhân viên cảm thấy quá mệt mỏi, căng thẳng thì họ sẽ có khuynh hướng rời khỏi tổ chức, nhưng lãnh đạo với phong cách chuyển đổi (được đặc trưng bởi sự truyền cảm hứng, sự đồng cảm và hy sinh) sẽ làm suy giảm mối quan hệ giữa sự suy kiệt cảm xúc và sự gắn kết; nghĩa là, cho dù nhân viên có chán nản, mệt mỏi thì người lãnh đạo biết truyền cảm hứng, biết quan tâm sẽ làm suy giảm nguy cơ bỏ việc của họ. Tương tự, Kemp, Kopp, và Kemp (2013) trong một nghiên cứu xem xét ảnh hưởng của sự căng thẳng, suy kiệt cảm xúc đến sự nhận diện tổ chức và sự gắn kết của tài xế xe tải chuyên nghiệp cũng cho kết quả là sự suy kiệt cảm xúc có tác động tiêu cực đến sự gắn kết của nhân viên.

Trong một môi trường làm việc năng động như môi trường làm việc của các công ty đa quốc gia, việc tiếp xúc với nhiều nền văn hoá khác nhau đã trở thành tất yếu. Theo đó, năng lực của đội ngũ lao động cũng được đánh giá với các tiêu chí rõ ràng, kèm theo nhiều điều kiện ràng buộc. Đây là nơi mà thành tích lao động cũng như cơ hội học tập, thăng tiến sẽ dựa theo sự nỗ lực từng cá nhân. Điều này tạo ra áp lực cạnh tranh giữa các nhân viên và làm họ dễ rơi vào tình trạng căng thẳng dẫn đến mệt mỏi và suy kiệt cảm xúc, đồng thời làm họ không có năng lượng để phấn đấu cũng như không còn mong muốn gắn kết với doanh nghiệp. Theo, Deniz, Noyan, và 
Ertosun (2013), từng loại cam kết cụ thể sẽ quyết định mức độ cam kết của nhân viên với tổ chức. Khi người lao động quá chán nản, mệt mỏi và không còn động lực để làm việc (quá suy kiệt cảm xúc) thì họ sẽ không ở lại tổ chức vì niềm vui (gắn kết tình cảm) hay vì cảm giác và quan niệm rằng một nhân viên trung thành là phải gắn bó suốt đời với doanh nghiệp, việc mình ra đi là sự tổn thất cho doanh nghiệp (gắn kết đạo đức); việc nhân viên vẫn tiếp tục duy trì làm việc cho tổ chức là vì những lợi ích họ đang nhận được hoặc mong muốn nhận được. Vì vậy, giả thuyết sau được đặt ra:

Hla: Sụ suy kiệt cảm xúc có tác động ngược chiều đến sụ gắn kết về mặt tình cảm của nhân viên trong các công ty đa quốc gia

H1b: Sụ suy kiệt cảm xúc có tác động cùng chiều đến sự gắn kết về mặt lợi ích của nhân viên trong các công ty đa quốc gia

H1c: Sụ suy kiệt cảm xúc có tác động ngược chiều đến sụ gắn kết về mặt đạo đức của nhân viên trong các công ty đa quốc gia

\section{Mối quan hệ giữa sụ thích nghi và sụ gắn kết của nhân viên}

Sự thích nghi của một cá nhân được hiểu là khả năng có thể điều chỉnh hành vi của mình để phù hợp với sự thay đổi của môi trường (Griffin, Neal, \& Parker, 2007). Dựa vào đó, Bodla và Ningyu (2017) đưa ra khái niệm về sự thích nghi của nhân viên là khả năng điều chỉnh, sửa đổi hành vi của mình để phù hợp hơn với tổ chức. Griffin và cộng sự (2007) cho rằng từng tổ chức đều có những yêu cầu riêng biệt, và những yêu cầu này sẽ tạo môi trường làm việc và ảnh hưởng đến quan điểm cũng như hành vi và cách ứng xử của nhân viên. Để đạt được hiệu suất cao trong công việc, nhân viên cần nhận thức tốt các yêu cầu và sự thay đổi của tổ chức để dần thay đổi hành vi của mình. Bodla và Ningyu (2017) cũng cho rằng hiệu quả công việc cũng phụ thuộc vào khả năng thích nghi của nhân viên. Vì khả năng này làm cho nhân viên vượt qua khó khăn để hoàn thành nhiệm vụ và mang lại lợi ích cho tổ chức (Baba, Tourigny, Wang, \& Liu, 2009).

Nhân viên thích nghi hơn với tổ chức vì họ có động lực và mong muốn làm tốt công việc, họ quan tâm đến việc sáng tạo ra nhiều cách thức làm việc hiệu quả (Theo Weitz et al., 1986, được trích dẫn bởi Bande, Fernández-Ferrín, Varela-Neira, \& Otero-Neira, 2016). Khi nhân viên có động lực để làm việc, họ sẽ thiết lập ra nhiều mục tiêu và phấn đấu đạt mục tiêu đó và cố gắng vượt qua trở ngại, thách thức để thích nghi hơn với tổ chức. Thêm vào đó, nhân viên cũng được tạo điều kiện để thích nghi hơn bằng cách được đưa đi đào tạo nhằm đáp ứng mục tiêu cá nhân và mục tiêu của tổ chức; từ đó, họ cũng có tâm lý và mong muốn gắn kết hơn (Ito \& Brotheridge, 2005). Trong một nghiên cứu thực nghiệm 600 nhân viên toàn thời gian ở Canada về các yếu tố thúc đẩy sự thích nghi của người lao động được thực hiện bởi Bande và Fernández-Ferrín (2015), khả năng thích nghi sẽ tác động trực tiếp đến sự gắn kết với tổ chức vì tình cảm và ý định nghỉ việc của nhân viên. Ngoài ra, sự thích nghi cũng ảnh hưởng gián tiếp đến ý định nghỉ việc thông qua mong muốn duy trì là thành viên của tổ chức.

Trong các công ty đa quốc gia, nơi có môi trường làm việc vừa năng động vừa đầy áp lực, thì nhân viên cần cần có khả năng thích nghi để hòa nhập nhanh hơn và hiệu quả làm việc tốt hơn. Từ đó tạo động lực để họ gắn kết và cống hiến cho tổ chức. Khả năng thích nghi càng cao, nhân viên càng dễ dàng hòa nhập và yêu thích công việc cũng như yêu thích công ty (gắn kết tình cảm); từ đó dẫn đến nâng cao chất lượng công việc và gặt hái được nhiều thành công cả về mặt tinh thần lẫn vật chất (gắn kết lợi ích); đồng thời, tạo ra cảm giác có trách nhiệm với công việc và với sự phát triển lâu dài của doanh nghiệp (gắn kết đạo đức). Vì vậy các giả thuyết sau được đặt ra: 
H2a: Sụ thích nghi có tác động cùng chiều đến sụ gắn kết về mặt tình cảm của nhân viên trong các công ty đa quốc gia

H2b: Sự thích nghi có tác động cùng chiều đến sụ gắn kết về mặt lợi ích của nhân viên trong các công ty đa quốc gia

H2c: Sự thích nghi có tác động cùng chiều đến sụ gắn kết về mặt đạo đức của nhân viên trong các công ty đa quốc gia

\subsection{Mô hình nghiên cúu đề xuất}

Dựa vào thuyết "Bảo tồn nguồn năng lương" và các công trình nghiên cứu trước đây, mô hình nghiên cứu sau được đề xuất:

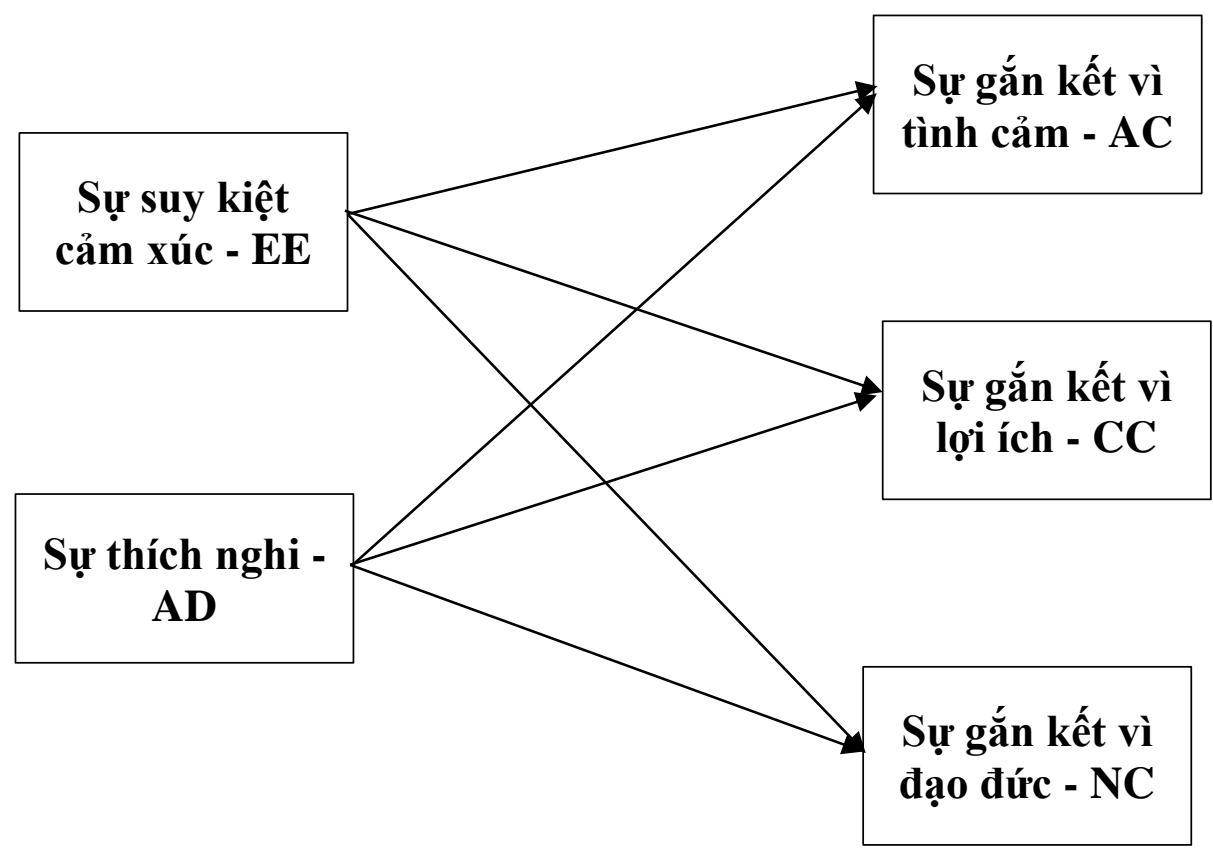

Hình 1. Mô hình nghiên cứu

Nguồn: Tác giả (2019)

\section{Thiết kế nghiên cứu}

Dựa vào việc hiệu chỉnh từ các nghiên cứu trước, mô hình đo lường gồm 28 biến quan sát. Trong đó, thang đo "Sự suy kiệt cảm xúc" - EE gồm 8 biến quan sát được kế thừa và hiệu chỉnh từ thang đo của Cropanzano, Rupp, và Byrne (2003); thang đo "Sư thích nghi - AD" gồm 3 biến quan sát được kế thừa từ thang đo của Bande và cộng sự (2016); thang đo "Cam kết vì tình cảm - $A C$ " gồm 5 biến quan sát, thang đo "Cam kết vì lợi ich - CC" gồm 6 biến quan sát và thang đo "Cam kết vì đạo đức - NC" gồm 5 biến quan sát được kết thừa từ thang đo của Meyer và Allen (1991).

Để thu thập dữ liệu, bảng câu hỏi được phát trực tiếp cho nhân viên người Việt đang làm việc trong các công ty đa quốc gia trên địa bàn thành phố Hồ Chí Minh. Phần mềm SPSS 25.0 (kiểm độ tin cậy của thang đo, phân tích nhân tố khám phá) và Amos 20.0 (phân tích nhân tố khẳng định, phân tích cấu trúc tuyến tính, kiểm định Bootstrap) được dùng để xử lý dữ liệu. Có 212 bảng khảo sát thu về đạt yêu cầu trong số 320 bảng khảo sát phát ra. Vì vậy, mẫu khảo sát cho đề tài này là 212 mẫu. 


\section{Kết quả nghiên cứu}

\subsection{Kiểm định độ tin cậy của thang đo và phân tích nhân tố khám phá EFA}

\section{Bảng 1}

Thang đo, hệ số Cronbach's Alpha và hệ số tải nhân tố

\section{Cấu trúc khái niệm và biến quan sát}

Hệ số tải Cronbach's

nhân tố Alpha

Sự suy kiệt cảm xúc - EE

0.912

Công việc làm tôi cảm thấy kiệt sức.

0.939

Vào cuối ngày làm việc, tôi cảm thấy năng lượng bị cạn kiệt.

Tôi cảm thấy mệt mỏi khi mỗi buổi sáng thức dậy tôi nghĩ mình phải 0.699 đối mặt với một ngày làm việc mới.

Làm việc với con người cả ngày thực sự làm tôi cảm thấy căng thẳng. $\quad 0.761$

Tôi cảm thấy thất vọng vì công việc của mình.

Tôi cảm thấy mình đang làm việc quá sức.

Làm việc trực tiếp với đồng nghiệp gây quá nhiều căng thẳng cho tôi.

0.741

Tôi cảm thấy như mình đang căng thẳng tột độ.

\section{Khả năng thích nghi - AD}

0.877

Tôi nghĩ thích nghi tốt với những thay đổi trong tổ chức cũng như 0.876 trong công việc.

Tôi có thể đối phó được với những thay đổi trong công việc cũng như 0.880 trong tổ chức.

Tôi học được những kỹ năng cần thiết để giúp đồng nghiệp và giúp 0.762 chính mình thích nghi tốt với sự thay đổi.

\section{Sự gắn kết vì tình cảm - $\mathrm{AC}$}

Tôi nghĩ mình sẽ làm việc cho công ty này lâu dài.

0.782

Tôi tự hào nói với bạn bè những lời lẽ tốt đẹp về công ty.

Tôi thấy những vấn đề của công ty cũng là vấn đề của tôi.

Tôi tự nguyện phấn đấu để giúp công ty thành công hơn.

Tổ chức này có rất nhiều ý nghĩa với cá nhân tôi.

\section{Sự gắn kết vì lọii ích - CC}

Nếu tôi nghỉ việc, tôi sẽ bị mất các cơ hội mình đang có.

Dù muốn nhưng tôi cảm thấy nghỉ việc lúc này sẽ gây khó khăn cho tôi. 


\section{Cấu trúc khái niệm và biến quan sát}

Hệ số tải Cronbach's

nhân tố Alpha

Nhiều thứ trong cuộc sống của tôi sẽ bị ảnh hưởng nếu lúc này tôi 0.934 quyết định nghỉ việc.

Nếu tôi không đầu tư quá nhiều vào công việc hiện tại, tôi đã xin nghỉ 0.800 ở công ty này.

Việc tiếp tục ở lại công ty là điều tôi mong muốn nhất.

Nếu tôi xin nghỉ, tôi khó tìm được một việc khác tốt hơn.

0.715

\section{Sự gắn kết vì đạo đức - NC}

Tôi cảm thấy có lỗi nếu xin nghỉ việc trong thời gian này.

0.748

Tôi không nghỉ vì tôi thấy mình có trách nhiệm với công ty.

Tôi tiếp tục làm việc tại đây là vì tôi cho rằng lòng trung thành là 0.740 quan trọng và tôi cảm thấy có nghĩa vụ ở lại.

Ngay cả khi việc nghỉ việc là có lợi cho tôi, tôi cũng cảm thấy làm 0.765 điều đó là không đúng.

Mỗi người nên gắn bó với một tổ chức trong phần lớn cuộc đời làm 0.798 việc của mình.

Ghi chú: (*) Biến bị loại trong phân tích Cronbach’s Alpha do hệ số tương quan biến tổng bé hơn 0.3.

(**) Biến bị loại trong phân tích EFA do hiệu số tải giữa hai nhân tố bất kỳ bé hơn 0.3.

Nguồn: Kết quả nhân tích dữ liệu của tác giả (2019)

Thang được đo độ tin cậy bằng hệ số Cronbach's Alpha. Kết quả nghiên cứu cho thấy, sau khi loại các biến quan sát $\mathrm{AC} 4, \mathrm{CC} 5$ thì tất cả các thang đo đều đạt độ tin cậy với tất cả hệ số Cronbach's Alpha đều lớn hơn 0.8 và hệ số tương quan biến tổng của các biến quan sát còn lại đều lớn hơn 0.3 .

Trong phân tích nhân tố khám phá EFA, sau khi loại các biến quan sát EE5, EE8 và CC1 thì có có 5 nhân tố được trích, kết quả này phù hợp với mô hình ban đầu bao gồm 2 biến độc lập và 3 biến phụ thuộc; tất cả các biến đều có hệ số tải nhân tố lớn hơn 0.5 , hệ số Eigenvalue đạt 1.871 (lớn hơn 1); phương sai trích đạt $67.434 \%$ (lớn hơn 50\%). Hệ số KMO đạt 0.797 (lớn hơn 0.5 và nhỏ hơn 1 ). Kiểm định Bartlett's Test có giá trị sig bằng 0.000 (nhỏ hơn 0.05 ). Vì vậy, kết quả phân tích phù hợp với dữ liệu. 


\subsection{Phân tích nhân tố khẳng định CFA}

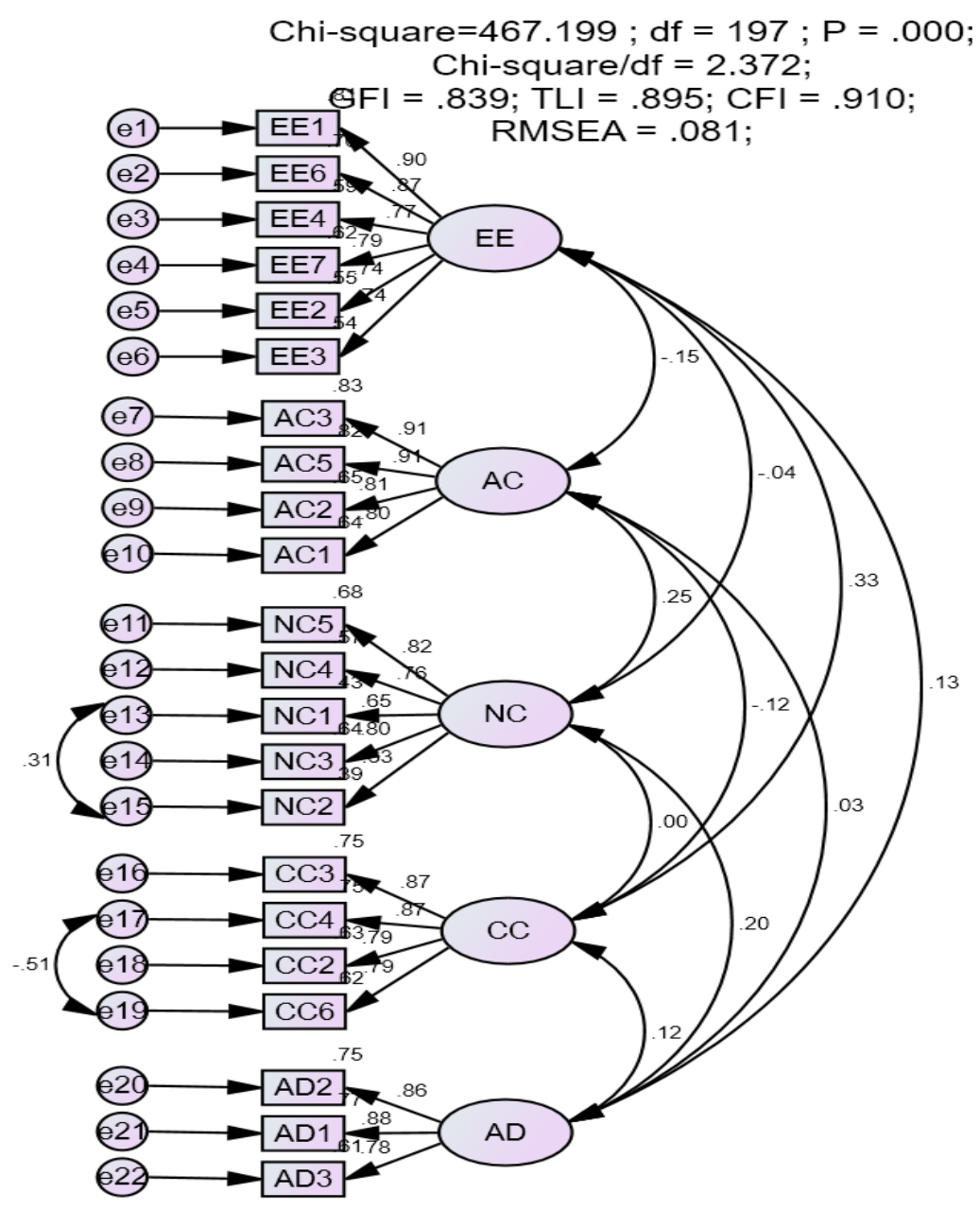

Hình 2: Kết quả phân tích CFA cho mô hình tới hạn (đã chuẩn hóa)

Nguồn: Kết quả phân tích dữ liệu của tác giả (2019)

Múc độ phù hợ chung: Phân tích CFA cho kết quả mô hình có giá trị $\mathrm{P}=0.000$, $\mathrm{CMIN} / \mathrm{df}=2.517<5$, đạt yêu cầu về độ tương thích. Các chỉ tiêu TLI $=0.895$ gần bằng $0.9, \mathrm{CFI}$ $=0.910>0.9$ và $\mathrm{RMSEA}=0.081$ gần bằng 0.08 . Nên mô hình tới hạn đạt được độ tương thích với dữ liệu thị trường.

Bên cạnh đó, trong phân tích CFA cần xem xét các chỉ số sau:

Giá trị hội tụ: Các trọng số đã chuẩn hóa đều $>0.5$ nên thang đo đạt giá trị hội tụ.

Giá trị phân biệt: Các giá trị $\mathrm{P}-\mathrm{value}$ đều $<0.05$ nên hệ số tương quan của từng cặp khái niệm khác biệt so với 1 ở độ tin cậy $95 \%$. Do đó, các khái niệm nghiên cứu đều đạt được giá trị phân biệt.

Tính đơn huớng: Ngoại trừ thang đo sự gắn kết vì lợi ích và sự gắn kết vì đạo đức, tất cả các thang đo còn lại đều đạt tính đơn hướng.

Độ tin cậy: Độ tin cậy của thang đo được đánh giá thông qua hệ số Cronbach's Alpha, hệ số tin cậy tổng hợp (Composite Reliability) hoặc tổng phương sai trích (Average Variance Extracted). 


\section{Bảng 2}

Tóm tắt kết quả kiểm định độ tin cậy của thang đo

\begin{tabular}{|c|c|c|c|c|}
\hline \multirow{2}{*}{ Thang đo } & \multicolumn{2}{|c|}{ Độ tin cậy } & \multirow{2}{*}{$\begin{array}{l}\text { Phương } \\
\text { sai trích }\end{array}$} & \multirow{2}{*}{ Kết luận } \\
\hline & Cronbach's Alpha & Tổng hợp & & \\
\hline Sự suy kiệt cảm xúc - EE & 0.912 & 0.902 & 0.645 & \multirow{5}{*}{ Đạt yêu cầu } \\
\hline Khả năng thích nghi - AD & 0.877 & 0.880 & 0.710 & \\
\hline Sự gắn kết vì tình cảm - AC & 0.915 & 0.918 & 0.737 & \\
\hline Sự gắn kết vì lợi ích - CC & 0.883 & 0.898 & 0.687 & \\
\hline Sự gắn kết vì đạo đức - NC & 0.861 & 0.854 & 0.538 & \\
\hline
\end{tabular}

Nguồn: Kết quả phân tích dữ liệu của tác giả (2019)

Hệ số Cronbach's Alpha của 5 thang đo đều lớn hơn 0.6 và nhỏ hơn 0.95 , độ tin cậy tổng hợp và phương sai trích đều lớn hơn 0.5 nên cả 5 thang đo đều đạt yêu cầu về độ tin cậy.

\section{4. Đánh giá sụ phù hợp của mô hình bằng mô hình cấu trúc tuyến tính SEM}
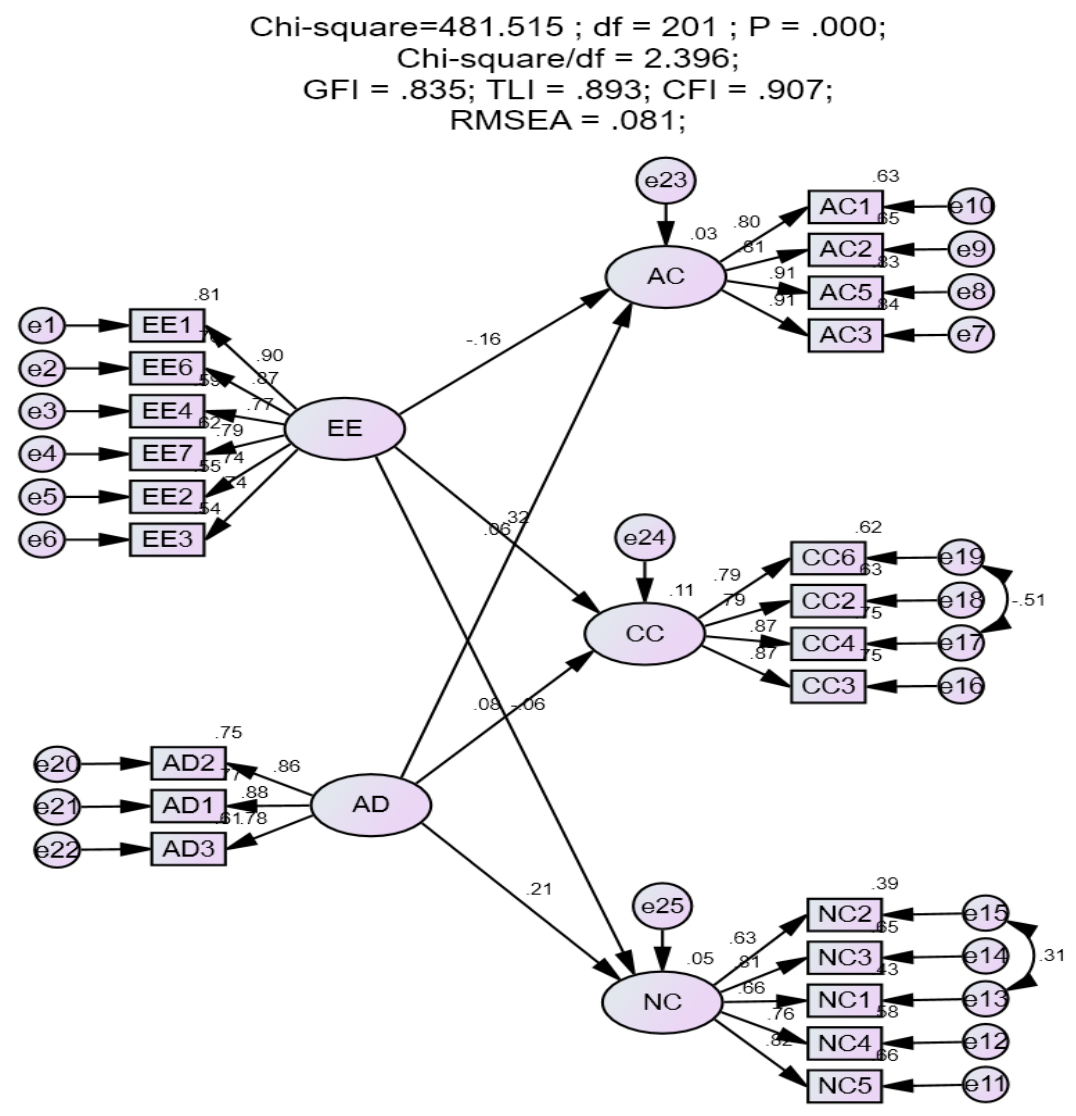

Hình 3: Kết quả SEM cho mô hình (đã chuẩn hóa)

Nguồn: Kết quả phân tích dữ liệu của tác giả (2019)

Mô hình có giá trị $\mathrm{P}=0.000$; giá trị $\mathrm{CMIN} / \mathrm{df}=2.396<5$; đạt yêu cầu cho độ tương thích. $\mathrm{TLI}=0.893$ gần bằng $0.9, \mathrm{CFI}=0.907>0.9, \mathrm{RMSEA}=0.081$ gần bằng 0.08 đạt yêu cầu. Vì vậy có thể kết luận mô hình phù hợp với dữ liệu thị trường. 


\subsection{Kiểm định giả thuyết}

\section{Bảng 3}

Kết quả kiểm định giả thuyết

\begin{tabular}{|c|c|c|c|c|c|c|c|}
\hline Giả thuyết & \multicolumn{3}{|c|}{ Mối quan hệ } & Ước lượng & $\begin{array}{l}\text { Ước lượng } \\
\text { (chuẩn hóa) }\end{array}$ & P-value & \\
\hline H1 & $\mathrm{AC}$ & $\leftarrow$ & $\mathrm{EE}$ & -.167 & -.155 & .034 & Chấp nhận \\
\hline $\mathrm{H} 2$ & $\mathrm{CC}$ & $\leftarrow$ & $\mathrm{EE}$ & .395 & .319 & $* * *$ & Chấp nhận \\
\hline H3 & $\mathrm{NC}$ & $\leftarrow$ & $\mathrm{EE}$ & -.071 & -.065 & .392 & Bác bỏ \\
\hline $\mathrm{H} 4$ & $\mathrm{AC}$ & $\leftarrow$ & $\mathrm{AD}$ & .070 & .056 & .455 & Bác bỏ \\
\hline H5 & $\mathrm{CC}$ & $\leftarrow$ & $\mathrm{AD}$ & .121 & .084 & .244 & Bác bỏ \\
\hline H6 & $\mathrm{NC}$ & $\leftarrow$ & $\mathrm{AD}$ & .261 & .206 & .009 & Chấp nhận \\
\hline
\end{tabular}

Nguồn: Kết quả phân tích dữ liệu của tác giả (2019)

Đối với tác động của sự suy kiệt cảm xúc đến sự gắn kết của nhân viên người Việt trong các công ty đa quốc gia, một giả thuyết đề xuất không được chấp nhận (sự suy kiệt cảm xúc tác không tác động đến sự gắn kết vì đạo đức) trong khi có $2 / 3$ giả thuyết được chấp nhận (sự suy kiệt cảm xúc tác động đến sự gắn kết vì tình cảm và vì lợi ích). Theo Meyer và Allen (1991), trong ba khía cạnh của sự gắn kết thì gắn kết vì đạo đức là biến có tương quan yếu nhất đến hành vi của người lao động vì biến này thường ít gắn với hiệu quả lao động. Khi nhân viên thật sự yêu thích công việc hay vì những lợi ích mong đợi mà kết quả công việc mang lại, họ sẽ phấn đấu để có thành tích tốt hơn. Vì vậy, kết quả trong nghiên cứu này có thể chấp nhận được. Theo đó, sự suy kiệt cảm xúc có tác động cùng chiều đến sự gắn kết vì lợi ích và sự suy kiệt cảm xúc có tác động ngược chiều đến sự gắn kết của nhân viên vì tình cảm. Nghĩa là khi nhân viên càng có cảm xúc suy kiệt thì họ cũng sẽ giảm sự yêu quý công việc và giảm sự gắn kết. Điều này có thể được giải thích như sau: Khi một cá nhân cảm thấy căng thẳng, mệt mỏi với công việc thì động lực để họ tiếp tục ở lại tổ chức là vì lợi ích nên hai biến này trong mô hình có mối quan hệ thuận chiều nhau.

Ngược lại, đối với tác động của sự thích nghi đến sự gắn kết của nhân viên, $2 / 3$ giả thuyết đề xuất không được chấp nhận. Nghĩa là, khả năng thích khi không ảnh hưởng đến sự gắn kết của người lao động vì tình cảm và lợi ích mà chỉ ảnh hưởng đến sự gắn kết vì đạo đức. Có thể thấy, làm việc trong một môi trường đa văn hóa, thu nhập cao như trong các công ty đa quốc gia thì đội ngũ lao động phải năng động, nhạy bén, sáng tạo, có trình độ chuyên môn lẫn trình độ ngoại ngữ. Những cá nhân như thế thường được giao những công việc quan trọng có vị trí quản lý. Vì vậy, họ sẽ gắn bó với doanh nghiệp vì những nhiệm vụ, trách nhiệm mà họ nắm giữ (gắn kết đạo đức).

\section{6. Ước lựng mô hình lý thuyết bằng Bootstrap}

Nghiên cứu sử dụng phương pháp Bootstrap với số lượng mẫu lặp lại $\mathrm{N}=500$. Kết quả ước lượng cho thấy các thang đo đều có $\mathrm{CR}<2$, có nghĩa độ chệch là rất nhỏ, không có ý nghĩa thống kê ở độ tin cậy $95 \%$. Như vậy ước lượng trong mô hình có thể tin cậy được.

\section{Kết luận và hàm ý quản trị}

Kết quả nghiên cứu cho thấy rằng nghiên cứu đã hoàn thành được 2 mục tiêu đã đề ra: (1) Kết quả kiểm định cho thấy, sự gắn kết của nhân viên (vì tình cảm và vì lợi ích) bị ảnh hưởng bởi sự suy kiệt cảm xúc và khả năng thích nghi của họ trong công việc sẽ ảnh hưởng đến sự gắn 
kết vì đạo đức; (2) Dựa vào kết quả nghiên cứu này, một số hàm ý tham khảo cho các công ty đa quốc gia trên địa bàn Thành phố Hồ Chí Minh nhằm nâng cao sự gắn kết của người lao động đối với tổ chức.

Thư nhất, đối với nhân viên người Việt đang làm việc trong các công ty đa quốc gia, sự gắn kết vì tình cảm sẽ bị tác động tiêu cực bởi sự suy kiệt cảm xúc. Vì vậy, để nhân viên luôn luôn vui vẻ, thoải mái, nhiệt tình, tràn đầy năng lượng và đặc biệt là luôn xem mình như một phần tử của tổ chức; thì họ cần được phân công việc hợp lý, đúng và đủ việc, tránh tình trạng dồn ép công việc cho những cá nhân có năng lực. Các chính sách chăm sóc sức khỏe như cung cấp những khóa học yoga, gym...sẽ là một biện pháp hữu hiệu để người lao động cân bằng sức khỏe, cuộc sống và công việc. Bên cạnh đó, việc cho nhân viên tự do sáng tạo trong công việc cũng là một biện pháp hữu hiệu để họ thể hiện bản thân và yêu quý công việc nhiều hơn. Văn hóa làm việc cũng là một yếu tố cần được xem xét. Các thành viên trong công ty đa quốc gia thường sẽ đến từ nhiều nền văn hóa khác nhau nên rào cản văn hóa, đặc biệt là rào cản ngôn ngữ là vấn đề thường xuyên xảy ra. Để xóa bỏ những rào cản này thì người lao động phải tự thân trao dồi kiến thức chuyên môn và kỹ năng mềm; đồng thời, các hoạt động đội nhóm cũng nên được tổ chức thường xuyên để nhân viên có được cơ hội tiếp xúc, thấu hiểu và thông cảm với nhau nhiều hơn. Sự quan tâm của doanh nghiệp đến đời sống cá nhân của người lao động cũng là vấn đề tất yếu cần được xem xét. Công việc áp lực đôi khi làm cho nhân viên không có nhiều thời gian cho gia đình và bản thân. Vì vậy, nếu gia đình của họ được chăm lo tốt (bằng các chính sách như: bảo hiểm thân nhân, học bổng cho trẻ em...) thì nhân viên sẽ càng yêu quý doanh nghiệp và an tâm công tác. Thư hai, sự suy kiệt cảm xúc còn có tác động đến sự gắn kết vì lợi ích của nhân viên. Điều này cho thấy rằng, cho dù có sự mệt mỏi, chán nản, căng thẳng trong công việc, thậm chí là có ý định nghỉ việc nhưng nếu những lợi ích người lao động nhận được xứng đáng và bù đắp được với những công sức mà họ bỏ ra thì người lao động vẫn gắn kết với tổ chức. Vì vậy, tổ chức và nhà quản trị cần quan tâm đến những lợi ích, phúc lợi mà nhân viên nhận được từ công việc bao gồm cả lợi ích về mặt vật chất lẫn tinh thần. Đó không chỉ đơn giản là lương, thưởng và các chế độ phúc lợi mà còn là những trải nghiệm mà họ muốn có được. Bên cạnh việc trả thù lao công bằng với sức lao động thì nhà quản trị cần tạo điều kiện để nhân viên học hỏi, trao dồi kiến thức chuyên môn và kỹ năng mềm để họ có thể hoàn thiện bản thân. Thứ ba, khả năng thích nghi của nhân viên với những thay đổi trong công việc hay trong tổ chức sẽ ảnh hưởng cùng chiều đến sự gắn kết của họ vì đạo đức; nói một cách khác, người lao động càng có trách nhiệm hơn với công việc khi họ có khả năng thích nghi cao. Để giúp các thành viên mới dễ dàng hòa nhập với công việc và với tổ chức thì nhà quản trị các cấp từ cấp cao đến cấp quản lý trực tiếp cần quan tâm và thực hiện việc chỉ dẫn tận tình cho nhân viên mới cũng như có những sắp xếp, thay đổi phù hợp, cần thiết để các nhân viên cũ không cảm thấy bất công hay bất hợp lý. Tổ chức những khóa đào tạo là một trong những biện pháp cần thiết để giúp nhân viên thích ứng với sự thay đổi. Vì vậy, chất lượng của những khóa đào tạo cần được kiểm soát và nâng cao. Bên cạnh đó, việc thường xuyên kiểu tra hay mở các lớp nâng cao trình độ ngoại ngữ, đặc biệt là tiếng Anh, sẽ giúp các cá nhân chưa có kỹ năng ngoại ngữ tốt tự tin hơn trong giao tiếp, tránh những sai lầm trong công việc do rào cản ngôn ngữ gây ra đồng thời giúp nhân viên nhanh chóng thích nghi với tổ chức.

\section{6. Đóng góp, hạn chế của đề tài và hướng nghiên cứu tiếp theo}

Thành phố Hồ Chí Minh là khu vực nghiên cứu chính của đề tài nên tính khái quát còn chưa cao. Vì vậy, các nghiên cứu tiếp theo có thể mở rộng khảo sát sang các tỉnh thành, khác như Hà Nội, Đà Nẵng, Cần Thơ...

Do tâm lý của các đối tượng tham gia khảo sát cho rằng việc trả lời bảng câu hỏi là mất 
thời gian và không mang lại lợi ích chính đáng gì cho công việc của họ hay các thông tin được thu thập sẽ không được bảo mật nên nhiều cá nhân không nhiệt tình trong việc trả lời câu hỏi. Vì vậy, kết quả khảo sát ít nhiều bị ảnh hưởng.

Sự suy kiệt cảm xúc và khả năng thích nghi là hai yếu tố chính ảnh hưởng đến sự gắn kết của nhân viên mà đề tài nghiên cứu. Trên thực tế còn rất nhiều yếu tố khác ảnh hưởng đến ý định nghỉ việc hay gắn hết của người lao động như các chính sách của chính phủ, môi trường làm việc, $x u$ thế nghề nghiệp, tính cách cá nhân, các phúc lợi của doanh nghiệp, .... Các nghiên cứu tiếp theo có thể xem xét và đưa vào mô hình đề xuất các yếu tố này.

\section{Tài liệu tham khảo}

Allen, N. J., \& Meyer, J. P. (1990). The measurement and antecedents of affective, continuance and normative commitment to the organization. Journal of Occupational Psychology, 63(1), 1-18.

Baba, V. V., Tourigny, L., Wang, X., \& Liu, W. (2009). Proactive personality and work performance in China: The moderating effects of emotional exhaustion and perceived safety climate. Canadian Journal of Administrative Sciences/Revue Canadienne des Sciences de l'Administration, 26(1), 23-37.

Bande, B., \& Fernández-Ferrín, P. (2015). How and when does emotional intelligence influence salesperson adaptive and proactive performance? European Management Review, 12(4), 261-274.

Bande, B., Fernández-Ferrín, P., Varela-Neira, C., \& Otero-Neira, C. (2016). Exploring the relationship among servant leadership, intrinsic motivation and performance in an industrial sales setting. Journal of Business \& Industrial Marketing, 31(2), 219-231.

Bodla, A. A., \& Ningyu, T. (2017). Transformative HR practices and employee task performance in high-tech firms. Journal of Organizational Change Management, 30(5), 710-724.

Cole, M. S., \& Bedeian, A. G. (2007). Leadership consensus as a cross-level contextual moderator of the emotional exhaustion-work commitment relationship. The Leadership Quarterly, 18(5), 447-462.

Collings, D. G., \& Scullion, H. (2012). Global staffing. In Handbook of Research in International Human Resource Management (2nd ed.). England, UK: Edward Elgar Publishing.

Cropanzano, R., Rupp, D. E., \& Byrne, Z. S. (2003). The relationship of emotional exhaustion to work attitudes, job performance, and organizational citizenship behaviors. Journal of Applied Psychology, 88(1), 160-169.

Deniz, N., Noyan, A., \& Ertosun, Ö. G. (2013). The relationship between employee silence and organizational commitment in a private healthcare company. Procedia-Social and Behavioral Sciences, 99, 691-700.

Grayson, K. (1998). Customer responses to emotional labour in discrete and relational service exchange. International Journal of Service Industry Management, 9(2), 126-154.

Griffin, M. A., Neal, A., \& Parker, S. K. (2007). A new model of work role performance: Positive behavior in uncertain and interdependent contexts. Academy of Management Journal, 50(2), 327-347.

Hoang Trong, \& Chu, N. N. M. (2008). Phân tích dĩ liệu nghiên cứu với SPSS [Analyze research data with SPSS]. Ho Chi Minh, Vietnam: Nhà xuất bản Hồng Đức. 
Hobfoll, S. E. (1989). Conservation of resources: A new attempt at conceptualizing stress. American Psychologist, 44(3), 513-524.

Hobfoll, S. E. (2001). The influence of culture, community, and the nested-self in the stress process: Advancing conservation of resources theory. Applied Psychology, 50(3), 337-421.

Hur, W. M., Park, S. I., \& Moon, T. W. (2014). The moderating roles of organizational justice on the relationship between emotional exhaustion and organizational loyalty in airline services. Journal of Services Marketing, 28(3), 195-206.

Ito, J. K., \& Brotheridge, C. M. (2005). Does supporting employees' career adaptability lead to commitment, turnover, or both? Human Resource Management, 44(1), 5-19.

Karl, K. A., \& Peluchette, J. V. (2006). Does workplace fun buffer the impact of emotional exhaustion on job dissatisfaction?: A study of health care workers. Journal of Behavioral and Applied Management, 7(2), 128-141.

Kemp, E., Kopp, S. W., \& Kemp, E. C., Jr. (2013). Take this job and shove it: Examining the influence of role stressors and emotional exhaustion on organizational commitment and identification in professional truck drivers. Journal of Business Logistics, 34(1), 33-45.

Khong Loan (2019). Tỷ lệ nghi việc trong doanh nghiệp dụ báo tăng đến 24\% năm 2019 [The resignation rate in enterprises is forecast to increase to 24\% in 2019]. Retrieved October 10, 2019, from https://forbesvietnam.com.vn/quan-tri/ty-le-nghi-viec-trong-doanh-nghiepdu-bao-tang-den-24-nam-2019-7798.html

Mai Dan (2017). Thiếu hụt nhân tài đang diễn ra trầm trọng [The shortage of talent is happening seriously]. Retrieved October 20, 2019, from http://thoibaotaichinhvietnam.vn/ pages/xa-hoi/2017-11-14/thieu-hut-nhan-tai-dang-dien-ra-tram-trong-50352.aspx

Meyer, J. P., \& Allen, N. J. (1991). A three-component conceptualization of organizational commitment. Human Resource Management Review, 1(1), 61-89.

Mowday, R. T., Steers, R. M., \& Porter, L. W. (1979). The measurement of organizational commitment. Journal of Vocational Behavior, 14, 224-247.

Nguyen, T. D. (2011). Phưong pháp nghiên cúu khoa học trong kinh doanh [Scientific research method in business]. Hanoi, Vietnam: NXB Lao động - Xã hội.

Nguyen, T. D., \& Nguyen, T. T. M. (2011). Nghiên cứu khoa họ marketing - Úng dụng mô hình cấu trúc tuyến tính SEM [Marketing science research - Applying SEM linear structure model]. Hanoi, Vietnam: NXB Lao động.

Porter, L. W., Steers, R. M., Mowday, R. T., \& Boulian, P. V. (1974). Organizational commitment, job satisfaction, and turnover among psychiatric technicians. Journal of Applied Psychology, 59(5), 603-609.

Spahr, P. (2015). What is transformational leadership? How new ideas produce impressive results. Retrieved October 25, 2019, from St Thomas University Online website: https://online.stu.edu/articles/education/what-is-transformational-leadership.aspx

Tarique, I., \& Schuler, R. (2008). Emerging issues and challenges in global staffing: A North American perspective. The International Journal of Human Resource Management, 19(8), 1397-1415.

Wright, T. A., \& Cropanzano, R. (1998). Emotional exhaustion as a predictor of job performance and voluntary turnover. Journal of Applied Psychology, 83(3), 486-493. 